\title{
Pedagogy in Theory and Practice
}

\author{
Gunita Gupta
}

\begin{abstract}
Pedagogy can be understood as methods and practices of teaching, and/or a way of being with children. In this paper, I use critical exposition and narrative to reflect on Max van Manen's (2012) theory of pedagogy as a relationship between adults and children. My writing is organized into alternating sections of exposition (theory) and narrative (practice) to illustrate the interplay between thinking and doing that typifies pedagogical relationships, and to demonstrate how pedagogy unfolds in the unpredictable, unexpected, unprecedented, and unique actions each of us perform in the relational events of our being with children.
\end{abstract}

\section{Background}

From Latin and Greek, in ancient usage, a pedagogue was a slave who took children (boys) to and from school. Currently, pedagogy is understood as methods and practices of teaching, and/or a way of being with children. In this paper, I use personal narrative to reflect on Max van Manen's $(1982 ; 2008 ; 2012)$ theory of pedagogy, which he defines by a relational commitment between adults and children. Using alternating sections of critical reading and story, I show how pedagogical theory becomes incarnate in the unpredictable, unexpected, unprecedented, and unique relational events of our being with children.

\section{Pedagogues}

\section{In Theory}

"The pedagogue," Max van Manen (1982) writes, "is the adult who shows the child the way into the world" (p. 285). By this definition, as a parent I am a pedagogue to my own children. But, I am also a teacher: an adult to whom a roomful of other peoples' children look for guidance almost every day at 8:05 a.m. The origin of "teacher," as one who teaches, comes from an Old English word which means to show or instruct and can be conjured in the image of a person standing at the front of a room full of children, hanging map pulled down, using a long stick to point out, "You are here." I am sure you can imagine this scene.

The pedagogue is one who leads; the teacher is one who shows. Or, better yet, the teacher is a pedagogue who leads and shows the children in her care where they are, as they go. The crucial differences between the two positions being attention and intention: a heeding and a leading with purpose and care. But not simply leading them-taking them by the hand and pulling them along — but, walking with them, stopping here and there to point, to notice. 
I am a pedagogue: a teacher. I lead my students and they follow me-sometimes even literally.

\section{And Practice}

I was not one for whom the call of teaching was a loud cry in my head or heart. In fact, the decision I made to enter teacher education was more pragmatic than anything else. I was 37 years old and had accomplished almost everything I had set out to accomplish-professionally speaking, at least-and had found myself at somewhat of an impasse. But, in order to progress, I needed to build on my meagre education. As a one-year program, in addition to my undergraduate degree, teaching education was the natural answer. It seemed like the best application of my experience, diverse skill set, and talents.

My first assignment was covering for a maternity leave in a small school (750 students) with a predominantly South Asian population. I learned so much in those six months, and, what's more, I was hooked on teaching high school.

I finished out my first year of teaching in a special-needs classroom in a brand-new middle school. I was completely out of my comfort zone in that classroom, but I adapted. This is part of that skill set I knew I brought with me to teaching: I am a quick learner. Besides, it was only two months.

Year two began with another two-month contract in another, decidedly less affluent, middle-school, teaching Resource. By this point, I was itching to get back into a high school. I missed banter with young teens and helping the older kids negotiate life. I missed teaching different things in different blocks to different kids. But the job market was saturated, and my actual work experience was minimal. I simply wasn't competitive. So, I took a job teaching grades 6/7 for the rest of the year. The. Rest. Of. The. Year. What was I thinking?

At the time, I am sure I was thinking, "I can do this! How hard can this be? This is just a slightly younger grade than I am used to..." Let me tell you: teaching elementary school is IN NO WAY even remotely similar to high school. Talk about out of my element! I was SO out of my element I was in an entirely different periodic table!

Those eight months were the longest eight months of my life. Between negotiating parents who were younger than I was, demanding to know how I was going to teach their kids how to multiply when they couldn't; students who cried, were dirty, or both; and the various "parties," "assemblies," and "special occasions" important to eleven- and twelve-year-olds; I was ill-prepared, to say the least. Each morning, as I drove over the Trans-Canada Highway to that little, old school, I looked east wistfully and wished I could just pull off the road I was on and drive away.

It wasn't that I didn't enjoy myself each day. I did. And the students and I easily fell into a routine. Every morning, rain or shine, after the bell rang, we all trooped back outside and did numerous one kilometre laps of the schoolyard. Some kids ran. Some kids ambled. Many followed behind me. And a few walked with me and chatted the entire time. Back in the classroom, I also soon figured out what needed to be done and how to do it. I was a quick learner, after all.

The issue was the teaching itself-the professional aspect of the job. It wasn't what I wanted it to be, which was... what, exactly? I am not even sure. But it wasn't it. It seemed like I spent more time juggling personalities and tween-age crises than actually teaching anything. There was nothing wrong with this, but it was not what I signed up for, and I looked forward to moving on. 
When the year finally ended, I could not get out of there fast enough. I had a yearlong contract teaching in a high school the following September and I was thrilled. Finally, I would get to experience all I had imagined teaching would be.

Then, around August of that summer, a funny thing happened: I missed the kids. Immensely. Like, tears in my eyes kind of missing. I couldn't believe it! I quickly reminded myself of how exasperated they often made me with their pointless stories and non-sequiturs. And yet, here I was, barely six weeks later, reminiscing. Suddenly it occurred to me what a privilege it was to teach those kids, and I realized that I was honoured that I had been trusted with their care and education.

The complicated feelings that resulted from my temporary assignment as an elementary school teacher would prove to have profound effects on how I conceive what it means to be a teacher. Indeed, these feelings were the catalyst that prompted me to become more critical of the calling I had chosen and to pursue graduate studies. Soon, I began to consider seriously the difference between schooling and education, what it means to be a teacher, and what it means to teach. Who, I wondered, is a teacher and how do we recognize them?

It has crossed my mind more than once that it might be nice to return to elementary school and the challenge of being a teacher in a situation for which I was never prepared. It's not as though I now feel more prepared. On the contrary, as the gap (Levinson, 2018) between me and younger students increases, I am actually less likely to understand them. But, understanding kids does not a teacher make. In much the same way content knowledge does not instantly give one the ability to teach. I suppose what I now possess, that I did not then, is an appreciation of my job as an entity with blurred boundaries. To be a teacher, I learned, is to be in constant flux, ever-changing, always new, and wholly dependent on the children in the schoolyard-some running, some ambling, some chatting, all following.

\section{Pedagogy}

\section{In Theory}

Pedagogy is what a pedagogue does, and, by this, pedagogy might then be anything and everything any adult does in relation to a child with respect to leading them, showing them, or introducing them to the world.

Pedagogy resists theorizing, in van Manen's (1982) views, since it exists not in philosophy or theory, but in the world of people being with one another. Throughout his writing, van Manen $(1982 ; 2008 ; 2012)$ describes the goodness or rightness of pedagogical contact and the meaning inherent in the pedagogical relationship: "Pedagogy is the most profound relationship that an adult can have with a child" (p. 290) and "[p]edagogy involves us in distinguishing actively and/or reflectively what is good, life enhancing, and supportive from what is not good or damaging in the ways that we act, live, and deal with children" (p. 10). He describes the nature of pedagogy as "elusive" (1982, p. 287) and compares it to love and friendship by saying it, "is to be found in the experience of its presence" - that it, "is here and here and here, where an adult does something right in the beginning of a child" (p. 284). But, what if I don't always do something right?

I can choose to choose my words carefully, with care, caring to wonder about how they will be received. I can be deliberate with my teaching and speaking with these children to whom I am bound. I can 
deliberate my pedagogical being and be deliberate with that being. And even still, my human being and acting with them can have unintended enormous negative consequences - the likes of which I may never witness.

[I]t is important to realize that the explicit and the implicit influence may have enormous consequences. We simply cannot predict in childhood how the latency of pedagogical influence is felt and realized throughout life - even when the child has become an adult. (van Manen, 2012, p. 10)

I know that at the end of a busy day of teaching, I will reflect on all the moments when I was short or snappy with my students, and I will regret the things I said, or the tone in which I said them. Or I will regret the things I did not say and obsess over how I could have been kinder/more understanding/more compassionate/gentler...better. I don't always do "something right," and I fear this makes me a bad pedagogue but a human, nevertheless. Can I be both?

\section{And Practice}

She was tall, even at 13, towering above my measly five feet, four inches. She had the teenage girl trifecta: she was a natural athlete, intelligent and kind, and beautiful. She was also shy and, in the one term I had her, I only got to know her a little bit. She was, however, the kind of kid one impresses without letting on she has been affected. But when she showed up in my class a couple of years later, she was all smiles.

"Ms. G, you are one of my favourite teachers," she told me. "I am so happy to be in your class."

Of course I was pleased, who wouldn't be? But I didn't feel I had earned this title. Once again it struck me how much a teacher makes an impact on students - both positive and negative-without even knowing it, or meaning to. van Manen (2008) puts it well when he writes, "In everyday life in classrooms, the thousand and one things that teachers do, say, or do-not-do, all have practical pedagogical significance" (p. 1). In this sense, pedagogical significance is understood as an adult having an effect on a child. Obviously, I had affected her, and this had led her to my class all these years later. I was happy to see her, and I looked forward to getting to know her better. Since her class was small (21 students), and we had the whole year to become well acquainted, I looked forward to the challenge.

I can't quite recall the month it happened-though I am positive she recalls it perfectly. As I write this, it occurs to me that it must have been just before Christmas. For, in the affluent socioeconomic neighbourhood in which I teach, it was not unheard of for students and their families to take advantage of off-season rates and abscond to sunny locales before the winter break officially began. Regardless, at the time of the occurrence, she had been away from class for about a week, and I had not heard anything about whether she was taking an impromptu vacation. Such behaviour was unlike the conscientious student I knew, and I was feeling a bit put out by her unscheduled absence, when, one day, she was suddenly back.

It was a lab day, the day when students get to cook a recipe that they had watched me demonstrate. We went through the class as usual. Her class was the last block of the day and, after I had dismissed them, I went over to the demo-table sink and proceeded to do the stack of dishes I had waiting for me. 
As I began to wash, she walked up to me, and somehow it occurred to me she was going to give me her excuse for being away without notice. I was actually about to preempt her apologies with a snarky comment, but something held me back.

Instead, as she stood beside me, I simply said, "Hi... haven't seen you for a while..." I purposely wasn't looking at her as I spoke. Then she responded.

"Yeah, I know. I'm sorry, Ms. G. My mom died."

Time stopped. I finally looked at her. She had tears in her eyes. But, in that moment, I had no idea what to say.

Actually, that is not entirely true. A multitude of things ran through my head, not the least of which was the intense desire I had to take this five-foot-eleven, 15-year-old in my arms and hold her. In fact, I felt that, given the look on her face, physical contact was not just warranted, but necessary. But, what did I do? I faltered as I frantically ran through all the possible responses I could give, trying to find the one I should give.

As I write this, I don't even recall what exactly I said. I know I asked how (fast-acting cancer, one month from diagnosis to death), and how she was coping. I also know that I realized that I knew embarrassingly little about her family... about her. I felt like a fraud-both because I felt I had failed her as her "favourite teacher," and because I had failed myself by balking when she told me her mother had died suddenly. What bothered me the most about this last part was that, when the time came to behave like a human being, I was more worried about what was appropriate for the role of teacher I was in.

Now, you may not know me too well, but propriety is not something to which I give too much thought or reverence-which is not to say I go out of my way to push the envelope. Rather, as a teacher, I tend to view conventions critically. I prefer to determine what is best for all involved in a situation, as opposed to resorting to rote method or common expectations, especially if and when such behavioural expectations contradict the urging of one's humane inner voice.

In my practice, Parker Palmer's (1998) concept of the undivided self influences so much of what I believe about being and teaching. Palmer writes, "In the undivided self, every major thread of one's life experience is honoured, creating a weave of such coherence and strength that it can hold students and subject as well as self" (p. 15). This concept was, I thought, the cornerstone of my teacher identity. I was proud that I expertly traversed any division between my vocation and my self-that I had merged the two, and lived and breathed both my self and my teacher self. It was all one and the same, or so I believed, until that moment when I faltered. As I recount this, I am ashamed to conclude that when events outside my being finally called upon me to be present and authentic in my interactions with others - to be my whole self-I hesitated.

Yet, I am sure she did not even notice. Indeed, subsequent interactions between us have only been positive. She is a lovely and gracious child, and, with time and space, I believe I have been able to make up for my perceived inadequacies in that moment at the sink. But I can't deny it happened, and that it bothered me. It still bothers me-even though it likely has not crossed her mind since. But maybe this is a good thing?

Perhaps van Manen's (2012) ideas about pedagogy and reflection are relevant to my inability to let this go. He writes, "The mother, father, teacher learn to understand themselves in new ways as they are prompted to reflect on themselves and the children for whom they care" (p. 10). While embarrassing 
and regretful situations abound in a teacher's practice, the biggest mistake we can make is to let such situations fade into the past without reflection.

\section{Pedagogical Relationships}

\section{In Theory}

van Manen writes (1982) that, "childhood is something one must grow out of (educere: to lead out of)" (p. 285), implying that what flows from the pedagogue is education-that a pedagogue is an educator (even if not a teacher by profession) by virtue of the fact of her continued life and relationship to a child. He goes on, "[a]nd so my adulthood becomes an invitation, a beckoning to the child (educare: a lead into)," further implying that the simple fact of a life lived beyond childhood—and amongst childrennecessarily lends itself to the being of a pedagogue:

So, in spite of what we think parents or teachers do, pedagogy is something that is cemented deeply in the nature of the relationship between adults and children. In this sense, pedagogy is defined not so much as a certain kind of relationship or a particular kind of doing, but rather pedagogy is something that lets an encounter, a relationship, a situation, or a doing be pedagogic. All our pedagogic being with children is a form of speaking with them. (p. 285, emphasis in original)

To summarize, then, if I live long enough-most likely due to the diligence of (a) pedagogue(s) in my own life- - to exist in the world as an adult with other, smaller, younger beings and I speak with them, then my being becomes pedagogic. This is not over-simplification. In the world there are both children and adults. Because children are not born with an innate ability to care for themselves, or understanding of the world, adults are charged with leading them such that they survive into adulthood themselves, and can do the same for the next batch of children in their wake. And since humans have language as the mediator between themselves (their selfs), speaking with one another is necessary to the relationship. The proof, if you wish to look for it—though van Manen (1982, p. 290) does not feel the need exists-is in the thing itself: in the provenance of the human civilization as a series of relationships between adults and children; and in all the things that are said, remembered, and said again.

Through my reading and reflection, I understand that pedagogy is not necessarily a choice but, rather, a response to the children with whom I share relationships. My position as pedagogue results as much from my choice to be around them as it does from the chance interactions I have with kids in my everyday being. And pedagogy is a result of that choice...that being. There is no pedagogy when one is alone. van Manen (1982) is right: pedagogy is pretheoretical (p. 291). I cannot sit at home at my desk, determine pedagogy, and then go and make it so. I can only act in concert with, and in response to children. I can then reflect on what I have done by attempting to approach the being/doing/saying in remembrance, and use the understanding I glean to inform my actions in the future. 
Pedagogy in Theory and Practice

\section{And Practice}

In the year that I became a secondary school teacher, I also became a stepparent. The kids were 6 and 8 the summer their mother and I moved in together. When I first met my partner and she told me she had kids, I was pleased. While I never wanted to have them myself, I enjoyed children and looked forward to parenting. Indeed, I had turned to teaching after over a decade working with adults in varying capacities, because I imagined that spending my days with kids would allow me to be my enthusiastic and energetic self-something my peers often found odd or tiring. Plus, I looked forward to nurturing the ideals of the young in an effort to stave off any inevitable negativity for as long as possible. I looked forward to the same with my new charges at home, as well. I imagined sweetness and light. But it was not to be. At least not at bath time!

One of the many new duties I had as a parent was bathing the kids. We had a routine whereby they would take a bath before bed every night. This was both to wash off the day and to prepare them for bed by lulling them into a slight stupor using hot water and lavender-infused bath products. I often opted to bathe my 6-year-old stepson because he was smaller and, therefore, it seemed to me it would take less time.

Initially the task was pleasant (as long as one didn't expect to stay dry) and it gave me time both to chat with him about his day, as well as teach him how to bathe himself. As I washed his hair, for instance, in addition to assuring him (repeatedly) that I would not get shampoo into his eyes, I also explained to him exactly what I was doing. My thought was that after a few times, he would slowly be able to take over this part of the bathing process.

However, it quickly became apparent that, though I would verbalize my movements whilst washing his hair numerous times over a period of weeks (and then months), whenever he was asked to mimic the motions, he seemed unable to do much more that drop most of the shampoo off his hand into the tub. If he was successful in getting some of it to his head, he would then proceed to massage it with just his fingertips into only the crown of his head for approximately six seconds, before plunging under the water to wash it off. Not that there was much to begin with. On the days he washed his own hair, as I was drying him off, I often sniffed his head to determine its state of cleanliness, and every time that funky door of young boy and playground dirt remained.

We went through this routine almost daily for what seemed like years. As he inexpertly washed his own head, sometimes I would joke, other times I would instruct, and often I would huff in total exasperation. It was amazing and disappointing to me that he just wasn't getting it. I thought perhaps I was explaining it wrong, so I tried different vocabulary and phrasing. I showed him my hands on my own head and let him feel them on his. I showed and explained to him how to keep his cupped palm level so the shampoo wouldn't drop into the tub when we filled it. Failing this, I squirted the shampoo directly onto his head-which succeeded somewhat-but he still refused to use his whole hand to work it into his hair. He seemed physically incapable! When I said, use your whole hand, he would then proceed to flatten them and move them like two paddles, rubbing only where his ears would be if he were a cat. It was enough to drive me insane. I did feel insane! Why was this so hard and why was it taking so long?!

And then, one day it happened. Suddenly, he could wash himself by himself. In fact, he even graduated from a bath to a shower. I don't even know exactly when it happened, the change was so gradual. He just kind of grew up and into his new role. As I write this, it seems obvious that this would happen. Indeed, at 12-years-old now, it seems like he has been bathing himself forever. But, clearly this is not true. There had been a time in the recent past when bath time was an annoyance we both had to endure. 
To be fair, the annoyance was all mine: I was annoyed that bath time was not more efficient, and I was annoyed that he couldn't or wouldn't learn to wash himself after repeated instruction. But, mostly, I was annoyed with myself for becoming annoyed because I knew that this was just one part of our parent/child relationship that would change over time, and I was not helping by being annoyed.

At the beginning of every new school year, I always go over the math of the year with my students. On the whiteboard I explain that there are 180 instructional days in a school year, that, in a linear high school, we meet for roughly half of these, and that at 70 minutes per meeting (give or take), all told, they will spend about 100 hours in my class. We then proceed to look at those 100 hours in perspective. I explain that 100 hours is about two and half weeks in a full-time job. It always surprises the kids to realize that the amount of time they spend in school, while it may seem like forever, amounts to very little in terms of their full, waking lives.

I go through the math partly to alleviate any students of unrealistic expectations they might have for themselves. I also go through it to demonstrate to them that 100 hours can be spent well or less well, but, that regardless, I will be there with them through it all. I tell them that, even though I will teach them many things, they, inevitably, will decide what they learn and when. I then tell them the story of my son learning to wash his own hair and ask them to recall their own graduation to self-sufficient bathing. To a child, no one ever quite remembers when it happens. Using the bathing story, we talk about how sometimes teaching can be deliberate but learning just doesn't follow - at least not right away-but that, if you give it time, eventually it comes. And by then, of course, something new to learn has replaced the old, and the cycle starts all over again.

I am ashamed to say that, while I know and teach this to my students, I struggle with it at home. I still get exasperated with my kids when it takes them years (it seems!) to learn to do something simple like turn off the lights when they leave a room, or write legibly. I find myself thinking them careless or thoughtless, even though I know they aren't being deliberately uncaring or unthinking. I have to remind myself continually that learning to be a fully functioning adult takes time, and that, at 12 and 14, they are not even remotely close. Moreover, I have to remind myself that I am there to help them as best I can, each and every time, for as long as it takes.

\section{Conclusions: Pedagogy of Story}

I began this paper by writing that pedagogy can be understood as methods and practices of teaching, and/or a way of being with children. Hopefully I have made clear my alignment with the latter definition. But, as the title of this piece suggests, pedagogy may also be construed as a theoretical stance that informs methods and practices, often in a disembodied way-pedagogy per se, if you will.

In his moving and thoughtful work, The Courage to Teach, Parker Palmer (1998) writes, "good teaching cannot be reduced to technique" (p. 10, emphasis in original). Yet, this is what we do when we construe pedagogy as a "packet of information at the end of an educational transaction" (p. 94) between teachers and the pedagogical course they take or theories they read.

Max van Manen's (1982; 2008; 2012) work, however, describes a theory of pedagogy that resists methodologizing or reducing to a list of instructions. He implores us to attend to the singular context of moments and the individual bodies that inhabit them in order to recognize them as pedagogical. Recognition means to know something based on previous experience. By noticing one's "everydayness 
and our immediate participation in daily life" (Meyer, 2012, p. 86), and then by telling stories about this interaction and reflecting upon them-only in this way do we recognize (our) pedagogy, and ourselves as pedagogical.

In 2021, as we embark on yet another year of living, teaching, and learning, where all of these things look starkly different to what many of us imagined when we first became students, teachers, and parents, we may be tempted to turn to theory for answers to our most pressing questions about how best to be pedagogical in the midst of a pandemic. My hope in writing this paper, is to show that theory alone is never enough.

Hannah Arendt (1993) writes that education "is where we decide whether we love our children enough not to expel them from our world, and leave them to their own devices" (p. 196). Taking Arendt's definition and marrying it to van Manen's theory: pedagogy, then, lives in the moment(s) when we decide how to practice that love.

\section{References}

Arendt, H. (1993). Between past and future. Penguin.

Levinson, N. (2018). The paradox of natality: Teaching in the midst of belatedness. In M. Gordon (Ed.), Hannah Arendt and education: Renewing our common world (pp. 11-36). Routledge.

Meyer, K. (2010). Living inquiry: Me, my self, and other. Journal of Curriculum Theorizing, 26(1), 85-96.

Palmer, P. J. (1998). The courage to teach: Exploring the inner landscape of a teacher's life. John Wiley \& Sons.

van Manen, M. (1982). Phenomenological pedagogy. Curriculum Inquiry, 12(3), 283-299.

van Manen, M. (2008). Pedagogical sensitivity and teachers practical knowing-in-action. Peking University Education Review, 1(1), 1-23.

van Manen, M. (2012). The call of pedagogy as the call of contact. Phenomenology \& Practice, 6(2), 8-34.

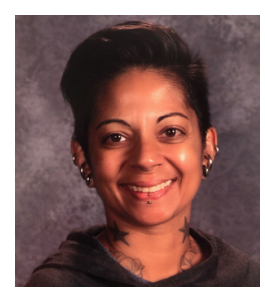

Gunita Gupta holds three degrees from the University of British Columbia and is currently pursuing her fourth. For her MA in curriculum studies, she wrote about the ways in which the existential project of teachers might be conceived as resistance to neoliberal forces in education. Her doctoral research in language and literacy education, however, focuses on food texts, epistemology, and the rhetorical construction of national nutrition education. In addition to graduate studies, Gunita is also a secondary teacher of both English and Foods in Langley, British Columbia. 